\title{
The Plant-Growth-Promoting Rhizobacterium Paenibacillus polymyxa Induces Changes in Arabidopsis thaliana Gene Expression: A Possible Connection Between Biotic and Abiotic Stress Responses
}

\author{
Salme Timmusk and E. Gerhart H. Wagner \\ Department of Microbiology, SLU (Swedish University of Agricultural Sciences), Box 7025, S-75007 \\ Uppsala, Sweden \\ Accepted 15 July 1999.
}

\begin{abstract}
This paper addresses changes in plant gene expression induced by inoculation with plant-growth-promoting rhizobacteria (PGPR). A gnotobiotic system was established with Arabidopsis thaliana as model plant, and isolates of Paenibacillus polymyxa as PGPR. Subsequent challenge by either the pathogen Erwinia carotovora (biotic stress) or induction of drought (abiotic stress) indicated that inoculated plants were more resistant than control plants. With RNA differential display on parallel RNA preparations from $P$. polymyxa-treated or untreated plants, changes in gene expression were investigated. From a small number of candidate sequences obtained by this approach, one mRNA segment showed a strong inoculation-dependent increase in abundance. The corresponding gene was identified as ERD15, previously identified to be drought stress responsive. Quantification of $\mathrm{mRNA}$ levels of several stress-responsive genes indicated that $P$. polymyxa induced mild biotic stress. This suggests that genes and/or gene classes associated with plant defenses against abiotic and biotic stress may be co-regulated. Implications of the effects of PGPR on the induction of plant defense pathways are discussed.
\end{abstract}

Additional keywords: dehydration, RT-PCR.

It is evident from a great number of reports that certain bacterial strains are beneficial for the growth of plants. A group of bacteria that display such effects are called plant growth-promoting rhizobacteria (PGPR). Paenibacillus polymyxa (previously Bacillus polymyxa; Ash et al. 1993), a common soil bacterium, belongs to this group. A range of activities has been found to be associated with $P$. polymyxa treatment, some of which might be involved in plant growth promotion (Timmusk et al. 1999, and references therein). The mechanism by which $P$. polymyxa exerts its beneficial effect is not understood: e.g., in certain P. polymyxa strains (Lindberg and Granhall 1984), atmospheric nitrogen fixation ability does not correlate with the observed growth-promoting effect (Lindberg et al. 1985).

Corresponding author: Salme Timmusk

E-mail: salme.timmusk@mikrob.slu.se
PGPR can affect plant growth directly or indirectly. Indirect promotion of plant growth occurs when PGPR antagonize or prevent the effects of phytopathogens or deleterious microorganisms (Glick 1994). The fact that no significant growth promotion was found in response to $P$. polymyxa inoculation under gnotobiotic conditions (Lindberg et al 1985), in the absence of pathogens or deleterious microorganisms, supports the idea that indirect growth-promoting mechanisms might be involved.

Most mechanisms proposed to explain indirect growth promotion suggest that the active principle may be a secondary bacterial metabolite that antagonizes pathogens. Metabolites include $\mathrm{HCN}$, siderophores, and antibiotics. P. polymyxa is known to produce antibiotic compounds, and inoculation with $P$. polymyxa suppresses several plant pathogens (Yuen et al. 1991; Oedjijono et al. 1993). Alternatively, direct competition for nutrients is a plausible scenario.

Recently, induced resistance to diseases, or plant "immunization," has received increasing attention (Uknes et al. 1992). This refers to a process in which plants exhibit an increased level of resistance to infection by a pathogen after appropriate stimulation (Ross 1961). Induced resistance can be triggered by, e.g., infection with a necrotizing pathogen (Kuc 1982; Ross 1961), or by treatment with certain chemicals, e.g., salicylic acid (SA) (White 1979). This response is referred to as systemic acquired resistance (SAR). Induced resistance can also be a result of root colonization by PGPR (Alström 1991; Wei et al. 1991). The latter response is called induced systemic resistance (ISR), and has been shown to protect against disease in several plant species (Thomashow and Weller 1995, and references therein; van Wees et al. 1997), but has so far been demonstrated only in pseudomonads. Mechanisms of induced resistance are, with some exceptions, still elusive. Maurhofer et al. (1994) have shown that ISR induced by the Pseudomonas fluorescens strain CHA0 is associated with pathogenesis-related (PR) protein accumulation. Later reports suggested that ISR may be controlled by an SA-independent pathway (van Wees et al. 1997; Pieterse et al. 1998). Lipopolysaccharides from bacterial outer membranes (van Peer and Schippers 1992), siderophores (Leeman et al. 1996), jasmonic acid (JA), and ethylene (ET) (Pieterse et al. 1998) have all been proposed to be involved in the induction of ISR. 
The present paper reports on a study that addresses changes of plant gene expression following inoculation by the rootinvading PGPR $P$. polymyxa. A gnotobiotic system was used to show that $P$. polymyxa isolates confer resistance to biotic (Erwinia carotovora challenge) and abiotic (drought) stress. With RNA differential display (RNA-DD) and reverse transcription-polymerase chain reaction (RT-PCR), genes were identified whose expression level was altered upon treatment with the PGPR.

\section{RESULTS}

A gnotobiotic system for studies of PGPR effects on plants.

Since the present study addresses changes in plant gene expression conferred, directly or indirectly, by treatment with PGPR, the choice of suitable model organisms was of importance. The PGPR used here, $P$. polymyxa, has a relatively wide host range. In addition to cereals, several dicots are susceptible to infection, including Arabidopsis thaliana (data not shown). A. thaliana was chosen as the model plant because it provides a good experimental system for genetic studies, and a great number of sequence entries in data bases are available, thus facilitating the identification of genes whose expression might be altered by the PGPR.

To evaluate putative plant-growth-promoting effects of previously isolated $P$. polymyxa strains, a gnotobiotic system was established. Defined and controlled plant growth medium and growth conditions were used in which effects of $P$. polymyxa on the target plant $A$. thaliana could be evaluated. The choice of a gnotobiotic system for this study was motivated by the need to exclude the uncontrolled variations in experimental conditions associated with studies carried out on plants grown in soil. It would also facilitate follow-up studies on metabolites produced by the PGPR that could be candidate mediators/elicitors of the effects observed.

As a test of putative protecting effects, PGPR-treated and control plants were challenged under biotic or abiotic stress conditions, respectively. E. carotovora subsp. carotovora (strain Scc 3193) was chosen as the biotic stress factor since it is a pathogen of very wide host range and therefore provides a system for the study of nonspecific plant-pathogen interactions. Drought was chosen as the abiotic stress factor.

\section{$P$. polymyxa isolates mediate protection of $A$. thaliana from pathogen attack and drought stress.}

Different strains of $P$. polymyxa had previously been isolated by Lindberg and Granhall (1984) and were shown to be effective as PGPR on cereals. Some of these isolates, denoted $P$. polymyxa $\mathrm{B} 2, \mathrm{~B} 3$, and $\mathrm{B} 4$, were tested in this study. In brief, plants were inoculated with a defined number of the PGPR. After a period of $24 \mathrm{~h}$, an antibiotic was added to both the inoculated and the control plants in order to reduce the

\section{Challenge}

\section{Erwinia carotovora}

\section{Pre-treatment Paenibacillus polymyxa}
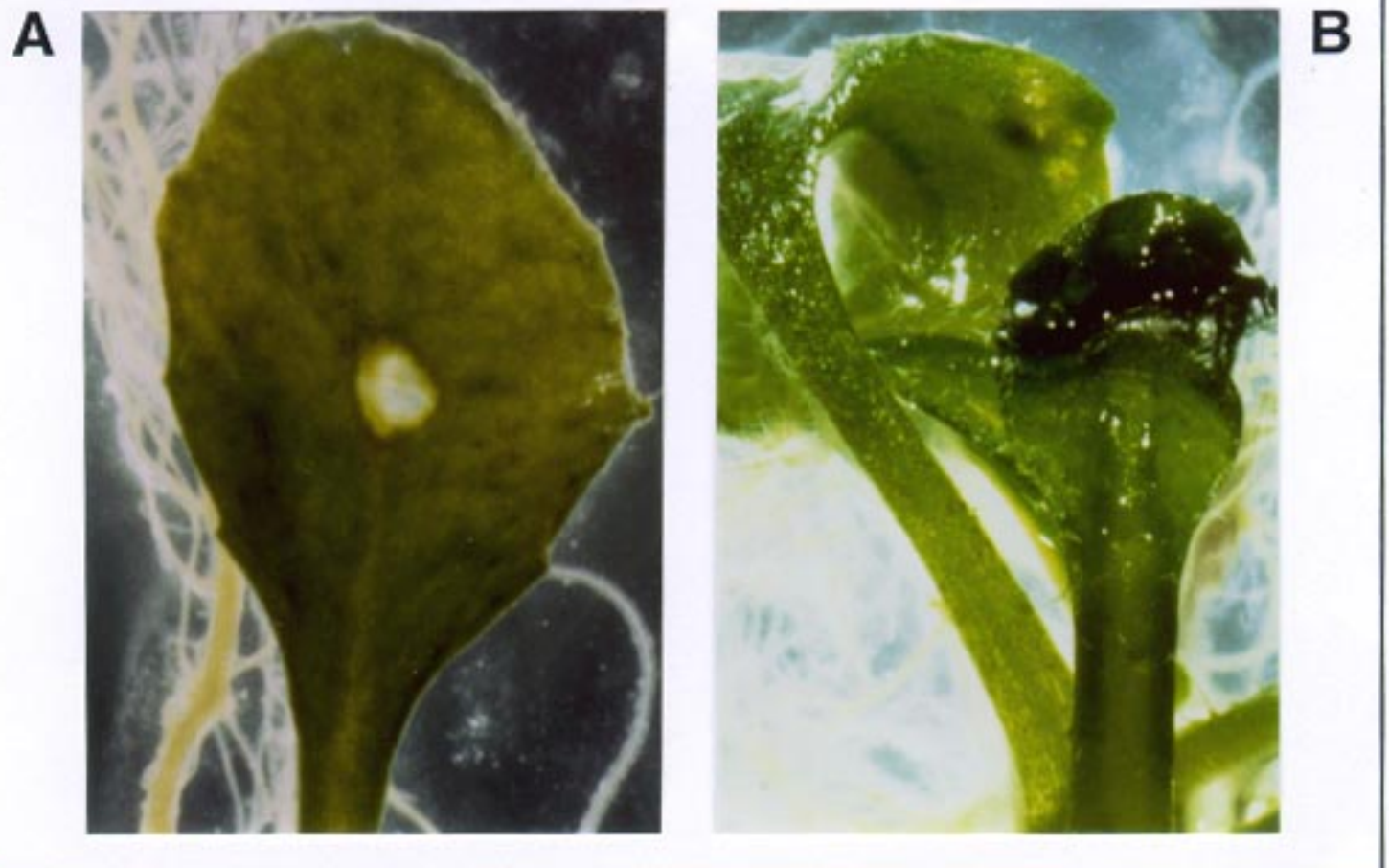

Fig. 1. Inhibition of soft rot symptom development by prior Paenibacillus polymyxa inoculation. Axenic seedlings of Arabidopsis. thaliana C24 were grown and inoculated with P. polymyxa (see Materials and Methods). Subsequently, plants were locally inoculated by Erwinia carotovora and cultured for $12 \mathrm{~h}$. The (A) P. polymyxa-treated plant shows signaticantly less severe characteristic symptoms than (B) a control plant that shows almost complete maceration at the same time point. 
number of free bacteria that had failed to enter plant roots. In pilot experiments, we observed that Arabidopsis plants treated with $P$. polymyxa showed mild stress symptoms: they were reproducibly smaller than mock-treated control plants, and their root system was clearly stunted. This effect was associated with PGPR infection and not antibiotic treatment, and was obtained, with similar efficiencies, in several $P$. polymyxa strains tested (B2, B3, and B4; data not shown).

The two types of stress were applied 1 week after PGPR treatment. For biotic stress treatment, one leaf per plantlet was inoculated by $E$. carotovora $\left(5 \times 10^{8} \mathrm{CFU}\right.$ per $\left.\mathrm{ml}\right)$ and plants were further grown for $24 \mathrm{~h}$ before analysis. Pre-treatment with $P$. polymyxa induced significant resistance: limited maceration was generally observed around the infection site (Fig. 1A), but the plants were still vital after 2 subsequent days of growth. In contrast, the leaves of control plants were already almost completely macerated at this time point (Fig. 1B). Viable count tests of E. carotovora extracted from leaves of PGPR-treated plants, at half-day intervals after infection, indicated decreasing numbers of the pathogen, compared with those in control plants (data not shown).

To study induced drought tolerance, a second set of plants was exposed to drought stress. Again, PGPR-treated plants were more resistant and tolerated drought stress significantly better than control plants. The latter showed severe wilting symptoms after 3 days of exposure to drought stress (Fig. 2).

\section{$P$. polymyxa treatment induces changes in plant gene expression.}

The observations reported above show that inoculation of $A$. thaliana by $P$. polymyxa $\mathrm{B} 2$ confers significant resistance to at least one plant pathogen and to drought treatment. Since this effect most likely is associated with changes in plant gene expression, we employed RNA-DD (Liang and Pardee 1992) to monitor changes in mRNA levels in plants associated with PGPR treatment. Total RNA was isolated, 1 week after inoculation (prior to stress treatment), in parallel from $P$. polymyxatreated and control plants. The mRNA was converted into cDNA and subsequently amplified by PCR to yield a number of radioactively labeled DNA fragments. The conversion of mRNA into first-strand cDNA was accomplished by RT with (separately) four anchored primers complementary to the poly-A tail. These primers, and the set of five arbitrary primers used to generate the DNA fragments in combination with the former, are shown in Table 1 (see Materials and Methods for details of the procedure). All PCRs with different primer combinations were performed in duplicate. PCR amplifications of $P$. polymyxa-treated and control samples were subjected to gel electrophoresis in parallel to permit easy comparison and to identify bands of altered intensity, depending on the treatment. A typical example of such an experiment is shown in Figure 3. From this gel and others (data not shown) containing fragments generated with a total of 20 primer combinations, frag-

\section{Challenge Drought}

\section{Pre-treatment Paenibacillus polymyxa}
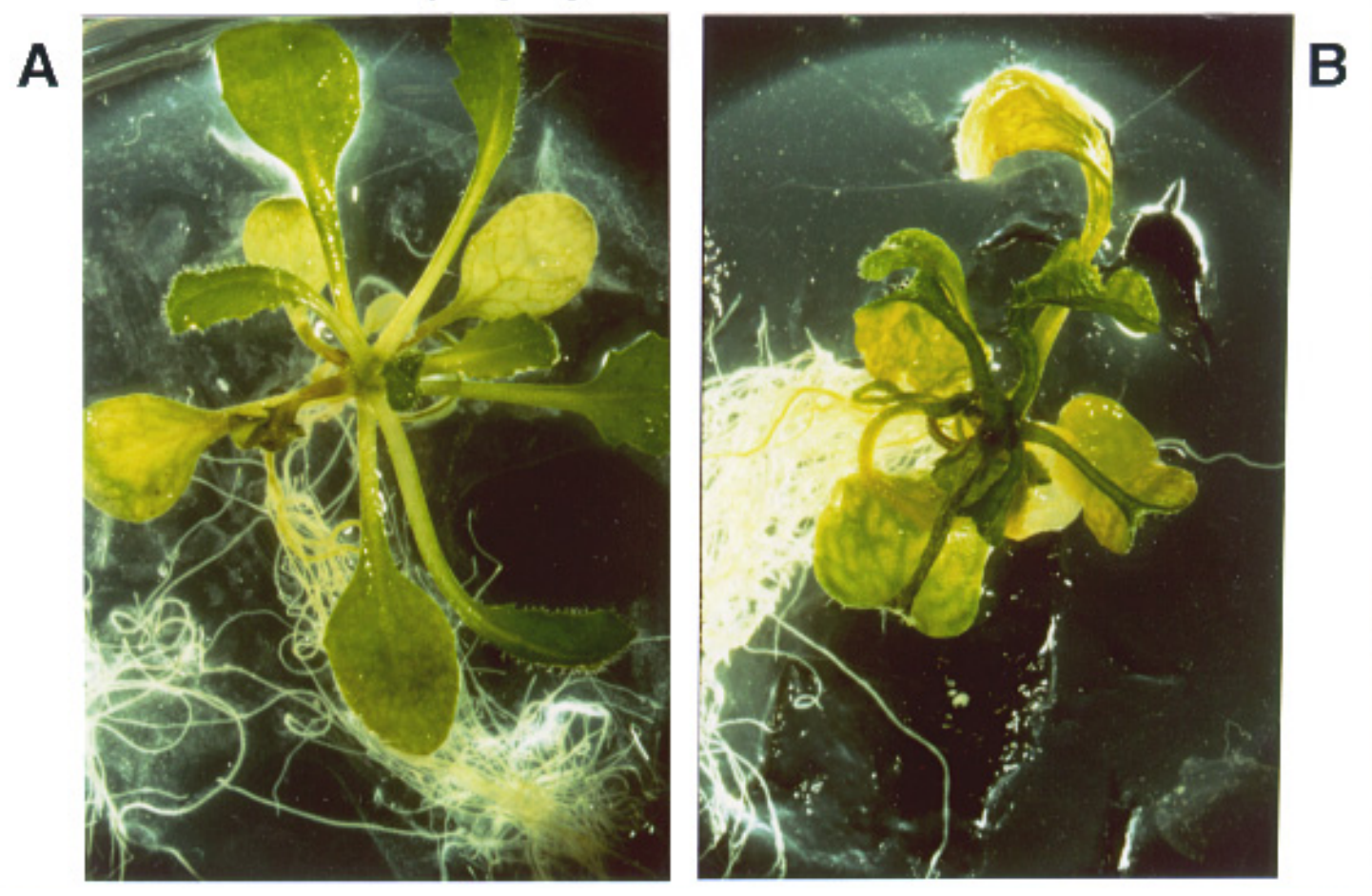

Fig. 2. Enhancement of drought stress tolerance by Paenibacillus polymyxa inoculation. Plants grown and inoculated as described in Figure 1 caption. Subsequently, exposure to drought stress was induced (Materials and Methods). The (A) P. polymyxa-treated plant shows less severe characteristic wilting symptoms than (B) an untreated control plant. 
ments of interest were eluted, re-amplified by PCR with the same set of primers, and subsequently cloned into the pCR-2 vector plasmid. To minimize the number of false positives, a hybridization screen method was employed (Consalez et al. 1996). Six insert sequences scored positive. The sequences of these inserts were determined and compared with entries available in genomic and cDNA data bases. One of these sequences was identified as a segment of the previously known gene ERD15 of A. thaliana (Kiyosue et al. 1994a).

\section{$P$. polymyxa treatment strongly increases expression of the drought-stress-induced gene $\mathrm{Erd15}$.}

As a confirmatory experiment, semi-quantitative RT-PCR was performed to test for differential expression of the sequences obtained. Primers derived from sequences internal to the inserts - thus different from the ones used to isolate the fragments-were used to amplify nested PCR fragments directly from the original first-strand cDNA obtained from treated and untreated plants. As an independent control for mRNA/cDNA content in samples, ACT2 (gene encoding Actin 2; An et al. 1996) was used. In this analysis, only one of the candidate sequences scored clearly positive in the RT-PCR test. Figure 4A shows that the gene segment of the ERD15 gene was differentially expressed: a fragment of correct size was obtained when cDNA was derived from $P$. polymyxa B2treated plants, whereas the samples from untreated plants yielded no visible PCR product. In contrast to this striking difference, the control sequence of the ACT2 gene was amplified to equal intensity when cDNA dilutions from both treated and untreated plants were used (Fig. 4B). Analysis of the other five insert sequences did not support significant differences in mRNA levels between the two treatments. Only one such example is shown in Figure 4C (clone 682).

The ERD15 gene sequence identified by the above protocol represented the 3 '-terminal mRNA segment, as expected from the primer sets used. Its sequence ( $217 \mathrm{bp}$ ) was compared with the published sequence (DDBG accession no. D30719). Of six independently obtained insert sequences, five were identical to the published sequence, whereas the remaining one carried both an insertion of $1 \mathrm{bp}$ and a 1-bp substitution. The 3'terminal 22 codons of the ERD15 reading frame were contained in the inserts, and the site of poly(A) addition was identical to the previously published sequence.

\section{$P$. polymyxa causes mild biotic stress.}

Since the differential expression of the ERD15 gene was unexpected, we decided to test two other known droughtresponsive genes. The genes $R A B 18$ (Lång and Palva 1992) and LTI78 (Nordin et al. 1993) display elevated expression levels upon drought stress. The RT-PCR experiment summarized in Figure 5 shows that expression of the abscisic acid (ABA)-responsive gene $R A B 18$ was fourfold higher in $P$. polymyxa-treated plants than in control plants, whereas the LTI78 gene was not differentially expressed.

Since we considered the possibility that $P$. polymyxa treatment might represent a mild biotic stress, other genes of interest were tested for differential expression. It has been shown that ET, JA, and SA have central roles in regulating defense gene expression (Vidal 1998). Hence, we analyzed the expression of marker genes for each of these pathways: HEL (hevein, ET pathway; Potter et al. 1993), ATVSP (vegetative storage protein acid phosphatase, JA pathway; Berger et al. 1995), and PR-1 (SA pathway; Uknes et al. 1992) were chosen. The RT-PCR experiments summarized in Figure 5 show that all three marker genes were overexpressed in plants previously treated with $P$. polymyxa, the induction levels varying from twofold to sixfold. We infer that this relatively small, but significant, increase is indicative of a "mild" biotic stress.

\section{DISCUSSION}

We report here on an investigation of changes in gene expression in the model plant $A$. thaliana induced by the PGPR

Table 1. Primers used

\begin{tabular}{|c|c|c|}
\hline Primer name & Use in experiment ${ }^{\mathrm{a}}$ & Sequence $\left(5^{\prime}-3^{\prime}\right)$ \\
\hline T12MA & RNA-DD + first-strand cDNA & See Materials and Methods \\
\hline T12MG & RNA-DD + first-strand cDNA & See Materials and Methods \\
\hline T12MC & RNA-DD + first-strand cDNA & See Materials and Methods \\
\hline T12MT & RNA-DD + first-strand cDNA & See Materials and Methods \\
\hline AP1 & RNA-DD / second primer & AGCCAGCGAA \\
\hline AP2 & RNA-DD / second primer & GACCGCGTGT \\
\hline AP3 & RNA-DD / second primer & AGGTGACCGT \\
\hline AP4 & RNA-DD / second primer & GGTAGTCCAC \\
\hline AP5 & RNA-DD / second primer & GTTGCGATCC \\
\hline ID-1 & RT-PCR / RAB 18 primer 1 & CATGCCATGGCGTCTTACCAGAACCGTCC \\
\hline ID-2 & RT-PCR / RAB 18 primer 2 & TTTACTGCAGTTAACAACGGCCACCACCGGGAAGC \\
\hline 3-PR & RT-PCR / PR-1 primer 1 & CСCCAAGCTTTTAGTATGGCTTCTCGTTCACATAAT \\
\hline 5-PR & RT-PCR / PR-1 primer 2 & CGCGGATCCTACTGGCTATTCTCGATTTTTAATCG \\
\hline 3-HEL & RT-PCR / HEL primer 1 & CCCAATGAGCTCATTGCCACAGTC \\
\hline 5-HEL & RT-PCR / HEL primer 2 & CGGTTACTGTGGTACCACCGCGGA \\
\hline AT-vsp3 & RT-PCR / ATVSP primer 1 & GGAGATGCGGTGAAGATATATGC \\
\hline AT-vsp5 & RT-PCR / ATVSP primer 2 & GTTGGTGTGACAAAATGGAAGC \\
\hline DR3-1-5 & RT-PCR / ERD-15 primer 1 & CCAGCGAAATGGGGAAACCA \\
\hline DR3-1-3 & RT-PCR / ERD-15 primer 2 & ACAAAGGTACAGTGGTGGC \\
\hline LTI-5 & RT-PCR / LTI-78 primer 1 & CTCAGAAACTTTCAAAGAGCTTAGAAAA \\
\hline LTI-3 & RT-PCR / LTI-78 primer 2 & AAGAGAGCGTTGGTTTGTACTTTGT \\
\hline M13-forward & Sequencing / PCR & GTTTTCCCAGTCACGA \\
\hline M13-reverse & Sequencing / PCR & CAGGAAACAGCTATGAC \\
\hline
\end{tabular}

${ }^{a}$ RNA-DD = RNA differential display; RT-PCR = reverse transcription-polymerase chain reaction. 
$P$. polymyxa. Inoculation with this root-invading bacterium conferred partial resistance to biotic (E. carotovora; Fig. 1) and abiotic (drought; Fig. 2) stress. From a number of gene segments detected by RNA-DD, only one scored positive: the ERD15 gene sequence was identified as a segment of its mRNA, abundantly present in PGPR-treated, but not untreated, A. thaliana (Fig. 4). This gene has previously been shown to be drought stress responsive (Kiyosue et al. 1994a). It was therefore surprising that induction of ERD15 could be induced prior to abiotic stress, i.e., merely by inoculation with $P$. polymyxa. The induction level of the ERD15 mRNA was high and estimated to be more than 50 times higher in samples from treated than from untreated plants (Fig. 4). This may suggest that the ERD15 protein carries out a second function in a defense against biotic stress, although no biochemical data are available to account for its putative role. A further possibility is that as $P$. polymyxa treatment results in stunted roots (see Results), intracellular water availability might be affected, thus inducing the dehydration-responsive ERD15 gene.

Since RNA-DD only yielded one differentially expressed gene, further characterization of the effect of inoculation was done by additional RT-PCR experiments performed on mRNA segments of stress-related genes. The twofold to sixfold induction of the JA-responsive ATVSP, the ET-responsive $H E L$, and the SA-responsive $P R-1$ genes bears the signature of a mild biotic stress induced by $P$. polymyxa inoculation. This effect is not unexpected, since these endophytic bacteria produce polygalacturonase and cellulase (S. Timmusk, unpublished) as well as pectate lyase (Forrest and Lyon 1990). Exo-

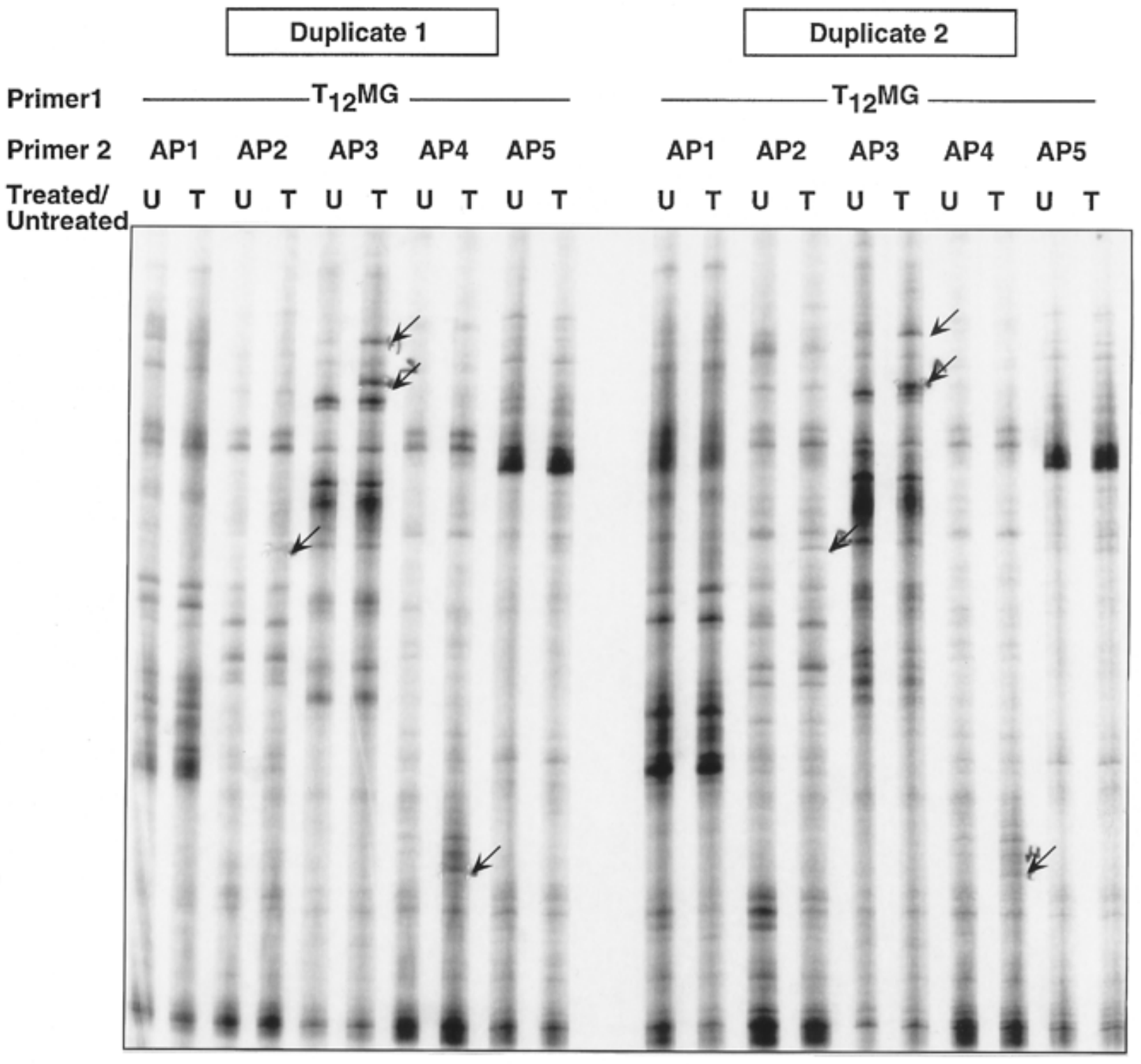

Fig. 3. Autoradiogram obtained from RNA differential display (RNA-DD) analysis of RNA isolated from Paenibacillus polymyxa-treated and untreated plants with five primer combinations (Materials and Methods). Primers used are indicated. U or T denote template RNA from untreated or treated plants, respectively. Two independent (duplicate) reactions were analyzed in parallel. Some bands of altered intensity, in comparison between T and U lanes, are indicated by arrows. Only bands that reproducibly showed up in repeated experiments were chosen for further analysis. 


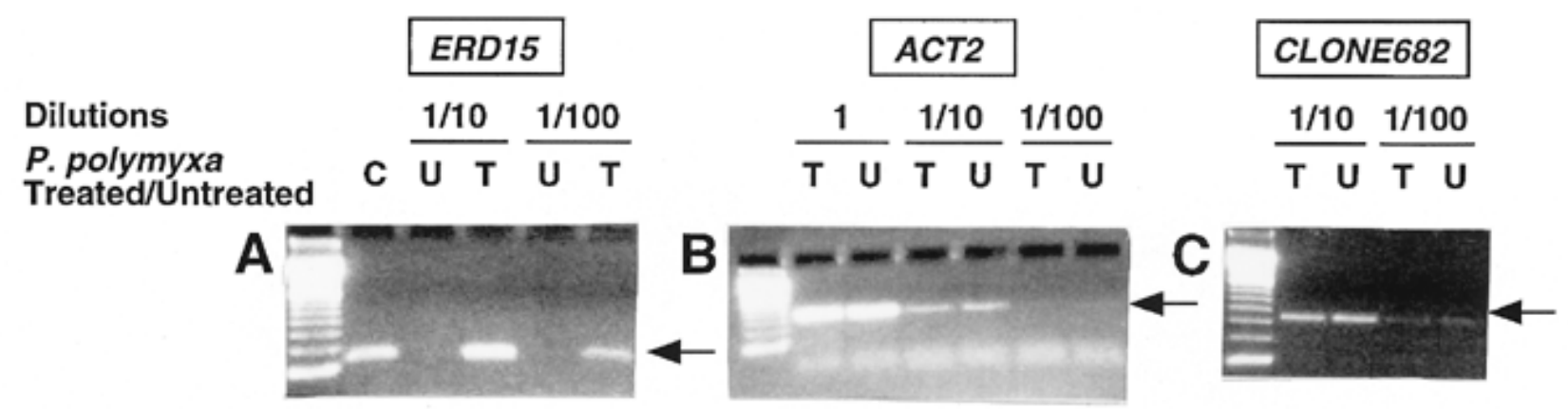

Fig. 4. ERD15 is differentially expressed in Paenibacillus polymyxa-treated plant tissue. Reverse transcription-polymerase chain reactions (RT-PCRs) were performed as described in Materials and Methods. Reaction mixtures were electrophoresed on $2 \%$ agarose gels, stained with ethidium bromide, and photographed. A, Primers complementary to sites within the insert sequence (internal primers) were used for RT-PCR to amplify a fragment from either cloned insert DNA used as a size control (C) or from RNA extracted from plants treated with $P$. polymyxa $(\mathrm{T})$. U denotes RT-PCRs carried out on RNA isolated from untreated plants. B, As controls for equal RNA content in the samples, RNA preparations were subjected to RT-PCR with a set of ACTIN2specific primers. C, One example of an analysis performed on one of the inserts (clone 682) that had scored positive in the pre-screening test (see Results for details). Primers sets were again derived from insert-internal sequences. Serial dilutions of template were used to ensure that results were not obscured by saturation of the PCR. Arrows indicate positions of expected fragments.

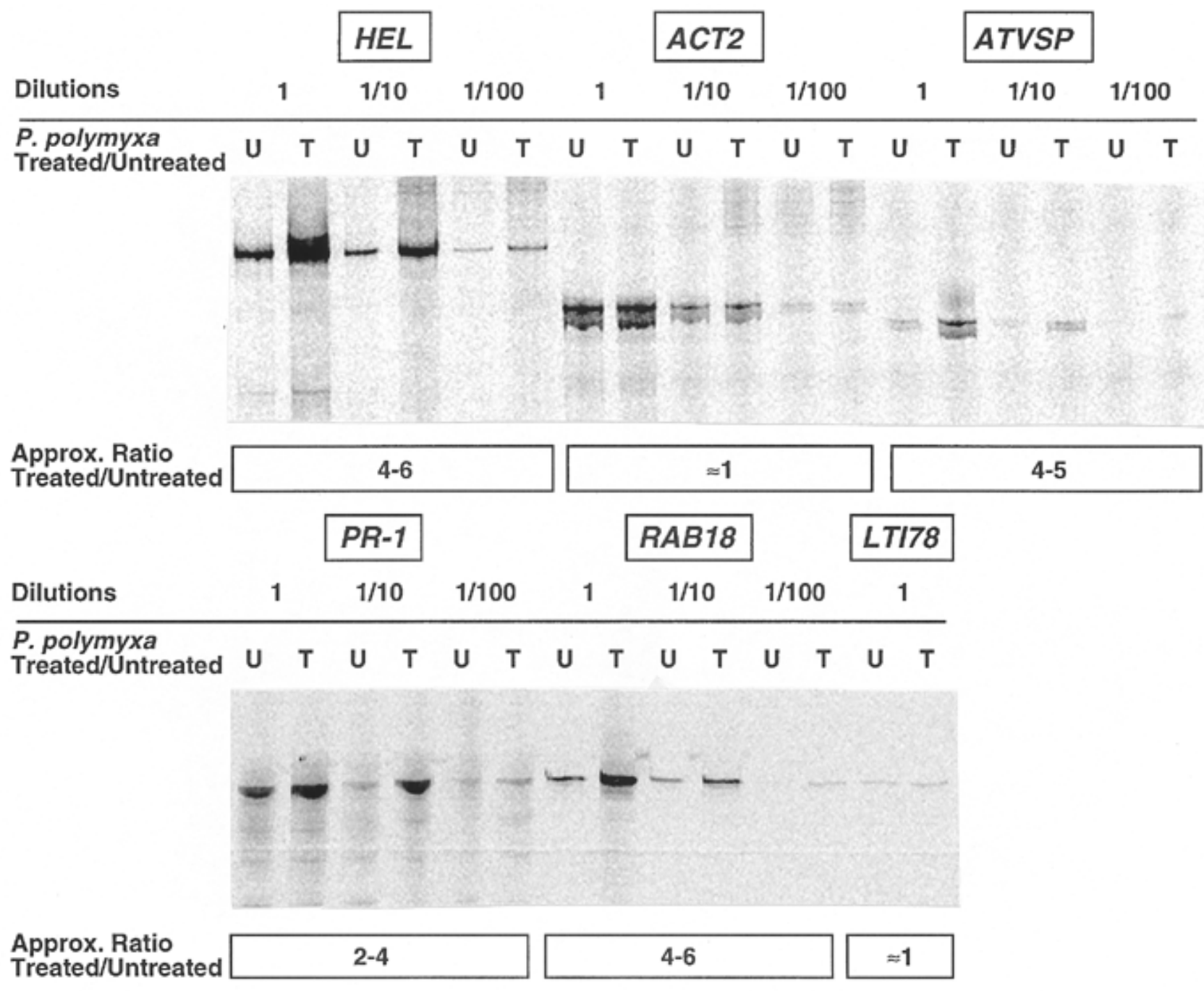

Fig. 5. Differential expression of additional stress-associated genes. Reverse transcription-polymerase chain reactions (RT-PCRs) were performed with sets of primers specific for biotic stress-associated genes (ATVSP, HEL, PR-1), abiotic stress-associated genes (RAB18, LTI78), and, as a control, ACT2. Template RNA was from Paenibacillus polymyxa-treated (T) or untreated (U) plants. Serial dilutions were used, and $\left[{ }^{35}\right.$ S]dATP was included in the PCRs for labeling of fragments. An autoradiogram is shown. Approximate values for ratio of intensities between bands found in $\mathrm{T}$ and $\mathrm{U}$ samples, determined by PhosphorImager analysis, are indicated below. 
enzyme preparations produced by E. carotovora have been implicated in triggering a defense response against the pathogen (Vidal et al. 1998), most likely via release of pectic fragments from the plant cell wall (Palva et al. 1993). Similarly, Maurhofer et al. (1994) showed that inoculation of plants by the root-invading Pseudomonas fluorescens strain CHA0 induced the synthesis of PR proteins. As $P$. polymyxa also induces gene expression of $P R-1$ (Fig. 5), this suggests that (i) the PGPR induce a mild biotic stress and (ii) this effect initiated a systemic response that resulted in partial protection from the pathogen upon subsequent challenge. Whether or not hydrolytic/pectinolytic enzymes are the main factor in the generation of elicitors in these cases and may represent a common denominator in induction of the systemic response is not yet established.

To assess the significance of the unexpected induction of $E R D 15$, two additional abiotic stress-related genes were tested for changes in mRNA levels. The RAB18 gene (also: LEA/ $D H N$; Welin et al. 1994) is induced by drought and ABA, whereas LTI78 (previously: LTI140) is strongly induced by low temperature, but only weakly by ABA and drought (Nordin et al. 1993). The RT-PCR experiments shown in Figure 5 indicate that $P$. polymyxa induced $R A B 18$ four- to sixfold, whereas $L T I 78$ was unresponsive. So far, this suggests that the unexpected induction of the ERD15 gene is not unique, since a second drought-responsive gene also showed an inoculation-dependent increase in expression level, albeit less pronounced. Since the present study did not include determinations of the levels of the various defense-related plant hormones, we cannot rule out that $\mathrm{ABA}$ is a key mediator in the induction of the ERD15 and RAB18 genes. We note, however, that the $E R D 15$ gene was previously isolated in a screen for dehydration-induced genes at a time point prior to the onset of ABA accumulation in the plant (Kiyosue et al. 1994b).

Hence, the most significant result obtained in this study suggests that application of a mild biotic stress can affect genes that hitherto have been associated with abiotic (here: drought) stress. This is strengthened by the protective effect of $P$. polymyxa inoculation upon plants when subjected to subsequent drought stress treatment (Fig. 2). It is not unexpected that different plant stress response pathways could be activated in concert: e.g., abiotic stress conditions, such as freezing and drought, may result in physical damage to plant tissue, which in turn should facilitate access of pathogens. Earlier work has indicated that abiotic stress can activate defenses against pathogens (biotic stress), whereas the reverse has rarely been found. So far, most stress-related proteins have not been analyzed for their biochemical activities, although some of them may carry out functions that are of importance in both types of stress situations. Moreover, some biotic and abiotic stress situations may result in similar physiological effects, and hence co-regulation of certain defense genes may be evolutionarily selected. For instance, several soil bacteria (e.g., Bacillus subtilis) produce osmolytes such as glycine betaine because they are subjected to frequent fluctuations in osmotic conditions (Lucht and Bremer 1994). Such compounds, if released within plant cells, could cause a mild osmotic stress by lowering the water potential outside the cell membrane. A wide variety of genes are induced by dehydration in order to protect plant cells from water deficit (Shinozaki and Yamaguchi-Shinozaki 1996, and references therein). Thus, bacterial root invasion could be perceived as a local dehydration through effects on the root system, which then might result in the induction of drought stress genes.

In conclusion, the results shown here indicate that inoculation by the PGPR $P$. polymyxa can protect $A$. thaliana against a bacterial pathogen and drought stress in a gnotobiotic system. This effect correlates with an increase in the expression not only of genes associated with biotic stress (PR-1, HEL, $A T V S P$ ) but also of those associated with drought stress (ERD15, RAB18). Even though more trivial explanations are possible (see above), these results may suggest that this bacterium can trigger both biotic and abiotic stress-related defense pathways, or that pathways are overlapping. The observed protection is consistent with a mild pathogenic effect. It is conceivable that plant growth promotion represents a tradeoff between maximal growth rate and an increased resistance toward pathogens. Whether the simultaneous induction of known drought response genes and pathogenesis-related genes is co-incidental or a beneficial selected trait is as yet unknown.

This study can only be considered a starting point in detailed investigations of PGPR effects on plants. Clearly, the identification of only one gene whose altered expression level was detectable by RNA-DD asks for additional examples. Furthermore, it will be of interest to test whether the striking increase in ERD15 expression is mediated by changes in the level of one (or several) of the key plant hormones.

\section{MATERIALS AND METHODS}

\section{Plant material and growth conditions.}

Seeds of $A$. thaliana ecotype $\mathrm{C} 24$ were surface sterilized by incubation in saturated and filtered aqueous calcium chlorate solution for $30 \mathrm{~min}$, followed by repeated washes in sterile, distilled water. Seeds were then sown on MS-2 medium (Murashige and Skoog 1962). Plants were replanted after germination and subsequently grown for 2 weeks in a growth chamber at $22^{\circ} \mathrm{C}$ with a 16 -h light regime.

\section{Plant inoculation by $P$. polymyxa.}

The $P$. polymyxa strains $\mathrm{B} 2, \mathrm{~B} 3$, and $\mathrm{B} 4$, isolated from the rhizosphere of wheat (Lindberg and Granhall 1984), were grown in L medium (Miller 1972) at $30^{\circ} \mathrm{C}$ to late log phase. Sequence analysis of a segment of $16 \mathrm{~S}$ rDNA confirmed the classification of the bacteria as $P$. polymyxa (data not shown). After 2 weeks of growth, plants were inoculated by soaking their roots in overnight cultures of $P$. polymyxa in L medium (approximately $10^{8}$ bacteria per $\mathrm{ml}$ ) for $24 \mathrm{~h}$; control plants were soaked in L medium. Both $P$. polymyxa-treated and untreated plantlets were then treated with Cefotaxim at $100 \mu \mathrm{g} /$ $\mathrm{ml}$ to reduce the number of bacteria around the roots. Plantlets were further grown for 1 week in Cefotaxim-containing medium. Bacterial growth in stems and leaves was evaluated by homogenizing four inoculated plants in $10 \mathrm{ml}$ of $10 \mathrm{mM}$ $\mathrm{MgSO}_{4}$ and plating of serial dilutions on $\mathrm{L}$ agar plates.

\section{Test of induced resistance to pathogen.}

One week after inoculation with $P$. polymyxa, six plants were locally inoculated by the E. carotovora strain Scc 3193 (Pirhonen et al. 1988). Bacterial growth and inoculation of plants were performed as described (Palva et al. 1994). In- 
oculated plantlets were further incubated, and E. carotovora growth in planta was evaluated at 12-h intervals as described above.

\section{Test of drought stress tolerance.}

Axenic seedlings of $A$. thaliana $\mathrm{C} 24$ were propagated and inoculated by $P$. polymyxa as described above. Plants were exposed to drought stress by opening the lids of the culture dishes for a period of 3 days.

\section{RNA-DD.}

Plant material (approximately $300 \mathrm{mg}$ per plant; combined from six plants) was ground in liquid nitrogen. RNA was extracted by a method based on LiCl-precipitation (Verwoerd et al. 1989). RNA samples were treated with DNase I as described in Sambrook et al. (1989) with RQ1 DNase (Promega, Madison, WI). Aliquots of total RNA (approximately $0.2 \mu \mathrm{g}$ ) were used for first-strand cDNA synthesis reactions that included MMLV reverse transciptase (Promega), dNTPs (20 $\mu \mathrm{M}$ ), and, separately, primers $\mathrm{dT}_{12} \mathrm{MG}, \mathrm{dT}_{12} \mathrm{MC}, \mathrm{T}_{12} \mathrm{MA}$, and $\mathrm{dT}_{12} \mathrm{MT}$ (all at $1 \mu \mathrm{M}$; Table 1). All primers were included in the differential display kit (Genhunter, Brookline, MA). "M" denotes a mixture of $\mathrm{dA}, \mathrm{dC}$, and $\mathrm{dG}$, thus rendering the anchored primers degenerate. Subsequently, five 10-mer primers were used, separately, in combination with the $\mathrm{dT}_{12} \mathrm{MN}$ primers in a total of 20 different reactions. Taq DNA polymerase (Perkin-Elmer, Foster City, CA) was used for amplifications, and PCR was performed in a Rapid Cycler (Idaho Technologies, Idaho Falls, ID). Labeling of the PCR fragments generated was done by inclusion of $\left[{ }^{35} \mathrm{~S}\right] \mathrm{dATP}$ (Amersham Pharmacia Biotech, Uppsala, Sweden). Reaction conditions were according to the manufacturer's manual. Aliquots of the reactions were run on $8 \%$ sequencing gels, followed by drying and exposure to X-ray film (Kodak, Rochester, NY). Bands of interest were excised from the gel, and the DNA fragments eluted. For re-amplification of the eluate, we used the same set of primers that had generated the band in question. This yielded DNA fragments for direct cloning into the pCR-2 vector plasmid (Invitrogen, San Diego, CA). Pre-screening of candidate inserts before RT-PCR analysis (see below) was done as published (Consalez et al. 1996).

\section{DNA sequence analysis.}

DNA sequences of inserts were obtained with a PCR cyclesequencing kit (Amersham Life Science, Cleveland, OH) on an ABI377 Sequenator (Perkin Elmer). Sequences were compared with available genomic and cDNA entries by BLAST searches.

\section{Semi-quantitative RT-PCR.}

To determine relative increases/decreases of mRNA abundance in parallel samples (treated/untreated), aliquots of initial RNA preparations were first reverse transcribed with genespecific primers (Table 1). Subsequently, serial dilutions of the cDNA were made and used for PCRs with pairs of gene sequence-specific primers. Serial dilutions were employed, since PCR amplification is exponential and thus band intensity differences must be measured before saturation of the amplification reaction is reached. Labeling of the fragments during PCR was done by inclusion of $\left[{ }^{35} \mathrm{~S}\right]-\mathrm{dATP}$, and fragments were separated on $2 \%$ agarose gels. Dried gels were exposed to X-ray film, and band intensities quantified by a PhosphorImager (Molecular Dynamics, Sunnyvale, CA).

\section{ACKNOWLEDGMENTS}

We are grateful to $\mathrm{U}$. Granhall for strains of $P$. polymyxa used in this study and for advice during the initial stages of this work. We are indebted to S. Vidal and B. Welin for RT-PCR primers and critical reading of the manuscript, R. Grönros for help with preparation of photographs, and D. Clapham for valuable discussions. We are grateful to P. Engström, U. Granhall, J. Schnürer, and J. Valkonen for critical reading of the manuscript. This work was performed with financial support from Stiftelsen Lantbruksforskning (SLF).

\section{LITERATURE CITED}

Alström, S. 1991. Induction of disease resistance in common bean susceptible to halo blight bacterial pathogen after seed bacterisation with rhizosphere pseudomonads. J. Gen. Appl. Microbiol. 37:495-501.

An, Y., McDowell, J. M., Huang, S., McKinney, E. C., Chambliss, S., and Meagher, R. B. 1996. Strong, constitutive expression of the Arabidopsis ACT2/ACT8 actin subclass in vegetative tissues. Plant J. 10:107-121.

Ash, C., Priest, F. G., and Collins, M. D. 1993. Molecular identification of rRNA group 3 bacilli using a PCR probe test. Antonie van Leeuwenhoek 63:253-260.

Berger, S., Bell, E., Sadka, A., and Mullet, J. E. 1995. Arabidopsis thaliana Atvsp is homologous to soybean $V s p A$ and $V s p B$, genes encoding vegetative storage protein acid phosphatases, and is regulated similarly by methyl jasmonate, wounding, sugars, light and phosphate. Plant Mol. Biol. 27:933-942.

Consalez, G. G., Corradi, A., Ciarmatori, S., Bossolasco, M., Malgaretti, N., and Stayton, C. 1996. A new method to screen clones from differential display experiments prior to RNA studies. Trends Genet. 12: 455-456.

Forrest, R. S., and Lyon, G. D. 1990. Substrate degradation patterns of polygalacturonic acid lyase from Erwinia carotovora and Bacillus polymyxa. J. Exp. Bot. 41:481-488.

Glick, B. R. 1994. The enhancement of plant growth by free-living bacteria. Can. J. Microbiol. 41:109-117.

Kiyosue, T., Yamaguchi-Shinozaki, K., and Shinozaki, K. 1994a. ERD15, a cDNA for a dehydration-induced gene from Arabidopsis thaliana. Plant Physiol. 106:1707-1712.

Kiyosue, T., Yamaguchi-Shinozaki, K., and Shinozaki, K. 1994b. Cloning of cDNAs for genes that are early-responsive to dehydration stress (ERDs) in Arabidopsis thaliana L.: Identification of three ERDs as HSP cognate genes. Plant Mol. Biol. 25:791-798.

Kuc, J. 1982. Induced immunity to plant disease. Bioscience 32:854860.

Lång, V., and Palva, E. T. 1992. The expression of a rab-related gene rab18 is induced by abscisic acid during the cold acclimation process of Arabidopsis thaliana (L) Heynh. Plant Mol. Biol. 20:951-962.

Leeman, M., den Ouden, F. M., van Pelt, J. A., Dirkx, F. P. M., Steijl, H., Bakker, P. A. H. M., and Schippers, B. 1996. Iron availability affects induction of systemic resistance to Fusarium wilt of radish by Pseudomonas fluorescens. Phytopathology 86:149-155.

Liang, P., and Pardee, A. B. 1992. Differential display of eucaryotic messenger RNA by means of the polymerase chain reaction. Science 257:967-971.

Lindberg, T., and Granhall, U. 1984. Isolation and characterization of dinitrogen-fixing bacteria from the rhizosphere of temperate cereals and forage grasses. Appl. Environ. Microbiol. 48:683-689.

Lindberg, T., Granhall, U., and Tomenius, K. 1985. Infectivity and acetylene reduction of diazotrophic rhizosphere bacteria in wheat (Triticum aestivum) seedlings under gnotobiotic conditions. Biol. Fertil. Soils 1:123-129.

Lucht, J. M., and Bremer. E. 1994. Adaptation of Escherichia coli to high osmolarity environments: Osmoregulation of the high-affinity glycine betaine transport system proU. FEMS Microbiol. Rev. 14:320 .

Maurhofer, M., Hase, C., Meuwly, P., Métraux, J.-P., and Défago, G. 1994. Induction of systemic resistance of tobacco to tobacco necrosis 
virus by the root-colonizing Pseudomonas fluorescens strain CHA0: Influence of the gacA gene and of pyoverdine production. Phytopathology 84:139-146.

Miller, J. H. 1972. Experiments in Molecular Genetics. Cold Spring Harbor Laboratory, Cold Spring Harbor, NY.

Murashige, T., and Skoog, F. 1962. A revised medium for rapid growth and bioassays with tobacco tissue culture. Physiol. Plant. 15:473-497.

Nordin, K., Vahala, T., and Palva, E. T. 1993. Differential expression of two related, low-temperature-induced genes in Arabidopsis thaliana (L.) Heynh. Plant Mol. Biol. 21:641-653.

Oedjijono, M., Line, A., and Dragar, C. 1993. Isolation of bacteria antagonistic to a range of plant pathogenic fungi. Soil Biol. Biochem. 25:247-250.

Palva, T. K., Holmström, K.-O., Heino, P., and Palva, E. T. 1993. Induction of plant defense response by exoenzymes of Erwinia carotovora subsp. carotovora. Mol. Plant-Microbe Interact. 6:190-196.

Palva, T. K., Hurtig, M., Saindrenan, P., and Palva, E. T. 1994. Salicylic acid induced resistance to Erwinia carotovora subsp. carotovora in tobacco. Mol. Plant-Microbe Interact. 7:356-363.

Pieterse, C. M. J., van Wees, S. C. M., van Pelt, J. A., Knoester, M., Laan, R., Gerrits, H., Weisbeek, P. J., and van Loon, L. C. 1998. A novel signaling pathway controlling induced systemic resistance in Arabidopsis. Plant Cell 10:1571-1580.

Pirhonen, M., Heino, P., Helander, I., Harju, P., and Palva, E. T. 1988. Bacteriophage T4 resistant mutants of the pathogen Erwinia carotovora. Microb. Pathog. 4:359-367.

Potter, S., Uknes, S., Lawton, K., Winter, A. M., Chandler, D., DiMaio, J., Novitzky, R., Ward, E., and Ryals, J. 1993. Regulation of a heveinlike gene in Arabidopsis. Mol. Plant-Microbe Interact. 6:680-685.

Ross, A. F. 1961. Systemic acquired resistance induced by localized virus infections in plants. Virology 14:340-358.

Sambrook, J., Fritsch, E. F., and Maniatis, T. A. 1989. Molecular Cloning: A Laboratory Manual. 2nd ed. Cold Spring Harbor Laboratory, Cold Spring Harbor, NY.

Shinozaki, K., and Yamaguchi-Shinozaki, K. 1996. Molecular responses to drought and cold stress. Curr. Opin. Biotechnol. 7:161-167.

Thomashow, L. S., and Weller, D. M. 1995. Current concepts in the use of introduced bacteria for biological control: Mechanisms and anti- fungal metabolites. Pages 187-235 in: Plant-Microbe Interactions, Vol. 1. G. Stacey and N. Keen, eds. Chapman and Hall, New York.

Timmusk, S., Nicander, B., Granhall, U., and Tillberg, E. 1999. Cytokinin production by Paenibacillus polymyxa. Soil Biol. Biochem. 31: 1847-1852.

Uknes, S., Mauch-Mani, B., Moyer, M., Potter, S., Williams, S., Dincher, S., Chandler, D., Slusarenko, A., Ward, E., and Ryals J. 1992. Acquired resistance in Arabidopsis. Plant Cell 4:645-656.

Van Peer, R., and Schippers, B. 1992. Lipopolysaccharides of plant growth-promoting Pseudomonas spp. strain WCS417r induces resistance in carnation to Fusarium wilt. Neth. J. Plant Pathol. 98:129-139.

van Wees, S. C. M., Pieterse, C. M. J., Trijssenaar, A., van 't Westende, Y. A. M., Hartog, F., and van Loon, L. C. 1997. Differential induction of systemic resistance in Arabidopsis by biocontrol bacteria. Mol. Plant-Microbe Interact. 10:716-724.

Verwoerd, T. C., Dekker, M. M., and Hockema, A. 1989. A small scale procedure for the rapid isolation of plant RNAs. Nucleic Acids Res. 17:2362.

Vidal, S. 1998. Molecular defense responses against the plant pathogen Erwinia carotovora. Ph.D. thesis. Swedish University of Agricultural Sciences, Uppsala, Sweden.

Vidal, S., Eriksson, A. R. B., Montesano, M., Denecke, J., and Palva, E. T. 1998. Cell wall-degrading enzymes from Erwinia carotovora cooperate in the salicylic acid-independent induction of a plant defense response. Mol. Plant-Microbe Interact. 11:23-32.

Wei, G., Kloepper, J. W., and Tuzun, S. 1991. Induction of systemic resistance of cucumber to Colletotrichum orbiculare by select strains of plant growth-promoting rhizobacteria. Phytopathology 81:1508-1512.

Welin, B. V., Olson, Å., Nylander, M., and Palva, E. T. 1994. Characterization and differential expression of dhn/lea/rab-like genes during cold acclimation and drought stress in Arabidopsis thaliana. Plant Mol. Biol. 26:131-144.

White, R. F. 1979. Acetylsalicylic acid (aspirin) induces resistance to tobacco mosaic virus in tobacco. Virology 99:410-412.

Yuen, G. Y., Godoy, G., Steadman, J. R., Kerr, E. D., and Craig, M. L. 1991. Epiphytic colonization of dry edible bean by bacteria antagonistic to Sclerotinia sclerotinum and potential for biological control of white mold disease. Biol. Control 1:293-301. 